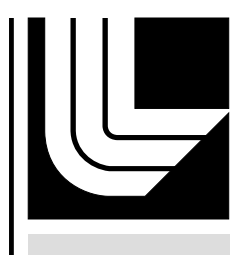

LAW RENCE LIVERMORE N A T IO N A L LABORATORY

\title{
UCRL-TR-213291
}

\section{Status of Current Plutonium Evaluations And an Update Plan for ENDL99}

David A. Brown

June 28, 2005 
This document was prepared as an account of work sponsored by an agency of the United States Government. Neither the United States Government nor the University of California nor any of their employees, makes any warranty, express or implied, or assumes any legal liability or responsibility for the accuracy, completeness, or usefulness of any information, apparatus, product, or process disclosed, or represents that its use would not infringe privately owned rights. Reference herein to any specific commercial product, process, or service by trade name, trademark, manufacturer, or otherwise, does not necessarily constitute or imply its endorsement, recommendation, or favoring by the United States Government or the University of California. The views and opinions of authors expressed herein do not necessarily state or reflect those of the United States Government or the University of California, and shall not be used for advertising or product endorsement purposes.

This work was performed under the auspices of the U.S. Department of Energy by University of California, Lawrence Livermore National Laboratory under Contract W-7405-Eng-48. 


\title{
Status of Current Plutonium Evaluations And an Update Plan for ENDL99
}

\author{
David Brown \\ Lawrence Livermore National Laboratory, Livermore, CA 94550 USA
}

(Dated: June 27, 2005)

\begin{abstract}
We review the current state of ENDL99, ENDF/B-VI.r8, JENDL-3.3, JEFF-3.0 and ENDF/B-VII. $\beta 0$ plutonium evaluations and lay out a tentative plan for updating all of the ENDL99 plutonium evaluations. In some specific cases, an evaluation for a particular isotope is of sufficient quality for us to adopt in ENDL99. More often, the quality of all evaluations for an isotope are low enough that we will need to perform a new evaluation.
\end{abstract}

\section{INTRODUCTION}

${ }^{239} \mathrm{Pu}$ is the fuel in a variety of applications. As ${ }^{239} \mathrm{Pu}$ burns, fission neutrons cause the creation and destruction of other plutonium isotopes. In order to understand the performance of various devices, it is critical to have accurate data for the creation and destruction cross sections on a variety of plutonium isotopes.

At LLNL, our cross section data is stored in the ENDL99 nuclear data library and is used in a host of application codes. In general, the set of plutonium evaluations in ENDL99 is quite out of date. Only ${ }^{239} \mathrm{Pu}$ was updated recently (in 1999 and again in 2001); the most recent evaluation for the other isotopes dates from 1982! We must update ENDL99 to reflect the large increase in our understanding of actinide physics in the past 2 decades.

Unfortunately, this task is not a simple one as the other nuclear data libraries are nearly as out of date as ENDL99. Here ENDF/B-VI.r8, ENDF/B-VII . $\beta 0, J E F F-3.0$ and JENDL-3. 3 are the libraries in which we are most interested. In this document, I outline the status of all of the plutonium cross section evaluations and lay out a path forward for updating ENDL99 and, to some extent, the other databases.

In order to update an isotope, it is not sufficient to just update the creation and destruction cross sections. The Optical Model and Hauser-Feshbach theory both combine to enforce a set of sum rules that all reaction cross sections must obey. Furthermore, common sense tells us that if one reaction is "shutting off" as we pass the threshold energy for another reaction, then both cross sections should have their features determined by that same threshold energy. In other words, an internally self consistent set of parameters must be used on all reactions on a nucleus. Thus, our strategy will be to maintain this internal self-consistency on all cross sections of an isotope to the greatest extent possible. Finally, we do not have the means to evaluate cross sections in the resonance region so will adopt existing evaluations if one of sufficient quality exists. In the next section, we go into more detail on how we assess the evaluations.

Here is a summary of our ENDL99 update plan:

${ }^{236} \mathrm{Pu}$ : Potentially adopt JENDL-3.3.

${ }^{237} \mathrm{Pu}$ : Redo, adopt JENDL-3.3 (n,res).

${ }^{237 m}$ Pu: Do from scratch.
${ }^{238} \mathrm{Pu}$ : Redo, adopt ENDF/B-VI.r8 (n,res).

${ }^{239} \mathrm{Pu}:$ Adopt ENDF/B-VII. $\beta 0$.

${ }^{240} \mathrm{Pu}$ : Potentially adopt JEFF-3.0 (n,res) $\rightarrow(\mathrm{n}, \mathrm{f}), \quad(\mathrm{n}, \gamma)$ ENDF/B-VI.r8 (n,tot), and rest of data from JENDL-3.3, but note that there is bad $(n, \gamma)$ and $(\mathrm{n}, \mathrm{f})$ data.

${ }^{241} \mathrm{Pu}$ : Redo, adopt JENDL-3.3 (n,res).

${ }^{242} \mathrm{Pu}$ : Redo, adopt JEFF-3.0 (n,res).

${ }^{243} \mathrm{Pu}$ : Redo, adopt ENDL99 (n,res), take fission evaluation from Ref [1].

${ }^{244} \mathrm{Pu}$ : Redo, adopt JENDL-3.3 (n,res), but note that there is conflicting $(n, f)$ data.

${ }^{245} \mathrm{Pu}$ : Do from scratch.

${ }^{246} \mathrm{Pu}$ : Redo, but parts of JENDL-3.3 may be salvageable.

As one can see, only ${ }^{239} \mathrm{Pu}$ has an evaluation of high enough quality to update ENDL99. Given that this is such a programmatically important isotope, we would like to test the performance of this isotope in critical assembly simulations and to verify that the outgoing particle distributions are reasonable before producing a floor library with this isotope altered.

Given the state of current evaluations, we believe that the next step should be to perform a "Z-chain" set of evaluations. This means that we attempt to evaluate all plutonium isotopes at the same time, within the same set of calculations. In this way, we can use an internally consistent set of parameters for all of the isotopes by, for example, tuning first and second chance fission on ${ }^{239} \mathrm{Pu}$ so that we can reuse these parameters to evaluate the fission of ${ }^{238} \mathrm{Pu}$ and ${ }^{237} \mathrm{Pu}$. If we proceed with this plan, we will do it in collaboration with LLNL's Nuclear Theory and Modeling Group and with Erich Ormand, the originator of the idea [2].

\section{How evaluations ARE ASSESSED}

We begin each isotope with a detailed discussion of our "plan of action" for the isotope. This includes an overview of the amount and quality of experimental data 
and how the evaluations compare to them. If an isotope can be "salvaged" from existing isotopes, this is explained here. Following this, we outline each evaluation for this isotope. A typical overview looks like this:

Evaluation library name

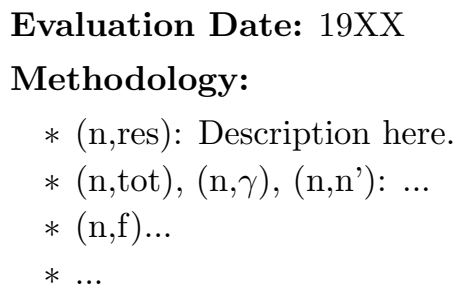

Comments:

Put comments here.

In the process of laying out an update strategy, we will encounter a number of problems with the existing evaluations. The most damaging problem is the lack of documentation. Since there is often insufficient data with which to judge a cross section evaluation, we must rely on an assessment of the evaluators methods. When no documentation exists, we have no basis for judgment and we must remove the evaluation from our consideration. The second most damaging problem is the "mix-and-match" nature of several evaluations. Often the evaluators did not have one modeling code capable of describing all of the reaction channels. In that case, they combined the results from several different codes to produce the entire reaction set. Unfortunately, when one does this, one must be careful to properly account for the competition between the different channels, computed within the different codes. In Ref. [3], one can see the effects on the $(n, \gamma)$ cross section when one does not correctly account for competition with fission.

When there is data for an isotope, we make a comparison between all of the data and the evaluations. The comparison to data is summarized in a table showing the evaluation's $\chi^{2}$. We compute the evaluation's $\chi^{2}$ in the usual manner:

$$
\chi^{2}=\frac{1}{N_{\text {data }}} \sum_{i=1}^{N_{\text {data }}} \frac{\left(\sigma^{e x p}-\sigma^{\text {eval }}\left(E_{i}\right)\right)^{2}}{\left(\delta \sigma_{i}^{e x p}\right)^{2}}
$$

The $\chi^{2}$ calculations come with the following caveats:

- We did not account for uncertainty in the incident energies

- We did not account for any kind of resolution effects or energy spread in the incident energy

- We comment that we did not compute covariance matrices for data

- We did not consider coupled (i.e. ratio) data

- We made no attempt to evaluate data itself. This implies that, for example, badly normalized data is not fixed. Given the information in data quality assessment, we can in remove bad data and may implement this feature when we believe the scoring is trustworthy.

These calculations are adapted from Ref. [4]. The quality assessments are broken down into relevant energy ranges: Thermal $\left(E<10^{-6} \mathrm{MeV}\right)$, Resonance $\left(10^{-6}<E<10^{-3}\right.$ $\mathrm{MeV})$ Unresolved Resonance $\left(10^{-3}<E<1 \mathrm{MeV}\right)$ and High Energy $(>1 \mathrm{MeV})$ regions.

\section{Evaluation Assessments}

$$
{ }^{236} \mathrm{PU}
$$

There are only five sets of $(n, f)$ data for this isotope and the one dataset with points in the resonance region is either grouped or has such a poor energy resolution that it is essentially useless for extracting the parameters for all but two resonances. The rest of the data does not have a dense enough distribution of points to perform a high quality fit. Given the quality of the data and the rather poor documentation of all three evaluations for this isotope, we suggest that this isotope should be reinvestigated within the proposed "Z-chain" re-analysis.

\section{ENDF/B-VI.r8}

Evaluation Date: 1995

\section{Methodology:}

* (n,tot): Sum of all other channels.

* (n,res): Unclear, probably based on systematics.

* $(\mathrm{n}, \mathrm{f})$ : Fit to data.

* (n,elas), (n, $\gamma), \quad\left(\mathrm{n}, \mathrm{n}^{\prime}\right), \quad(\mathrm{n}, 2 \mathrm{n}), \quad(\mathrm{n}, 3 \mathrm{n})$, $(\mathrm{n}, 4 \mathrm{n})$ : Adopt JENDL-3.2.

\section{Comments:}

We could not obtain a copy of the JENDL-3.2 evaluation, so are unable to comment further on the origin of this evaluation.

$\mathrm{JEFF}-3.0$

\section{Evaluation Date: 1982}

\section{Methodology:}

* (n,tot): Sum of other reactions.

* (n,res): Systematics, probably using $(\mathrm{n}, \mathrm{f})$ fitting results.

* (n,f): Fit using GENPAR code [5] for low energies, tuned Hauser-Feshbach calculation for high energies.

* (n,elas): Optical Model calculation.

* $(\mathrm{n}, \gamma), \quad\left(\mathrm{n}, \mathrm{n}^{\prime}\right), \quad(\mathrm{n}, 2 \mathrm{n}), \quad(\mathrm{n}, 3 \mathrm{n}), \quad(\mathrm{n}, 4 \mathrm{n})$ : Hauser-Feshbach calculation. 


\section{Comments:}

Low energy fit of fission appears to be same as ENDF/B-VI.r8.

JENDL-3. 3

Evaluation Date: 2002

\section{Methodology:}

* (n,tot): Optical Model calculation.

* (n,elas): Subtract all reactions from $(\mathrm{n}$, tot) .

* (n,res): (n,f) fit, rest done using model.

* (n,f): Hauser-Feshbach calculation tuned to reproduce high-energy data.

* (n, $\gamma), \quad\left(\mathrm{n}, \mathrm{n}^{\prime}\right), \quad(\mathrm{n}, 2 \mathrm{n}), \quad(\mathrm{n}, 3 \mathrm{n}), \quad(\mathrm{n}, 4 \mathrm{n})$ : Hauser-Feshbach calculation.

\section{Comments:}

The evaluation documentation seems to suggest that the Hauser-Feshbach calculation here is the same as in JENDL-3.2. If this is true than the disagreement between ENDF/B-VI.r8 and JENDL-3.3 is mysterious.

$$
{ }^{237} \mathrm{PU}
$$

There is no data for reactions on this isotope and no simple way to assess these evaluations. The ENDF/B-VI.r8 evaluation has internally consistent calculations, but it is not clear what the evaluators used for an optical model or fission model parameters. On the other hand, the JENDL-3.3 evaluation is clearer but the inter-channel competition is not properly accounted for in the $(\mathrm{n}, \gamma)$ and $\left(\mathrm{n}, \mathrm{n}^{\prime}\right)$ cross sections. We would like to revisit this isotope as part of the proposed "Z-chain" analysis.

ENDF/B-VI.r8

Evaluation Date: 1978

Methodology:

* (n,tot): Sum of other reactions.

* (n,res): Systematics.

* (n,elas): Optical Model calculation.

* (n,f), (n, $\gamma),\left(\mathrm{n}, \mathrm{n}^{\prime}\right),(\mathrm{n}, 2 \mathrm{n}),(\mathrm{n}, 3 \mathrm{n}),(\mathrm{n}, 4 \mathrm{n})$ : Hauser-Feshbach Calculation [6].

\section{ENDL99}

Evaluation Date: 1982

Methodology:

Unclear, no documentation given.

JEFF-3.0

Evaluation Date: 1982
Methodology:

Adopt ENDF/B-VI.r8.

JENDL-3.3

Evaluation Date: 1995

Methodology:

* (n,tot), $\quad(\mathrm{n}, \gamma), \quad\left(\mathrm{n}, \mathrm{n}^{\prime}\right): \quad$ HauserFeshbach/Optical Model calculations using CASTHY [7] and ECIS [8].

* (n,f), (n,2n), (n,3n), (n,4n): HauserFeshbach/Optical Model calculations using STAPRE [9] and ECIS [8].

* (n,res): Systematics.

* (n,elas): Subtract other reactions from $(\mathrm{n}$, tot)

\section{Comments:}

Since STAPRE was used for some of the reactions and CASTHY for others, there will be problems with competition between the various channels. Since $(n, f)$ is the largest channel and it is computed within the STAPRE set of calculations, we expect the competition problems to be largest with the $(\mathrm{n}, \gamma)$ and $\left(\mathrm{n}, \mathrm{n}^{\prime}\right)$ cross sections.

$$
{ }^{237 m} \mathrm{PU}
$$

There are no evaluations for this isotope, but there is a surrogate $(\mathrm{n}, \mathrm{f})$ data analysis from Younes and Britt [1]. We would like to investigate this isomer as part of the proposed "Z-chain" analysis.

$$
{ }^{238} \mathrm{Pu}
$$

There are sufficient data on $(\mathrm{n}, \mathrm{f}),(\mathrm{n}, \gamma)$ and $(\mathrm{n}, \mathrm{tot})$ at low energies to do a reasonable fit to (n,res). Furthermore, there is enough high energy $(n, f)$ data to fit the entire energy range from 1-20 MeV.

There are only two independent evaluations for this isotope performed since the late 1970's: ENDF/B-VI.r8 and JENDL-3.2. The ENDF/B-VI.r8 evaluation dates from the late 1970's so the evaluators did not have access to any of the recent high quality data. Furthermore, the evaluators did not state any details of their HauserFeshbach calculation, making it difficult to assess their modeling quality. Even so, this evaluation has the highest quality (n,res) data. The JENDL-3.2 evaluation (upon which JEFF-3.0 and JENDL-3.3 are based) is more recent but is composed of the results from several separate modeling efforts. As a result, we suspect that there may be competition problems in this evaluation. Given this, we would like to reinvestigate this isotope as part of the proposed "Z-chain" analysis.

ENDF/B-VI.r8 
TABLE I: Comparison of data to evaluations for ${ }^{236} \mathrm{Pu}$.

\begin{tabular}{l|c|c|c|c|c}
\hline \hline & & & \multicolumn{3}{|c}{$\chi^{2} / N_{\text {data }}$} \\
\cline { 4 - 7 } Energy Range & Reaction & $N_{\text {data }}$ & ENDF/B-VI.r8 & JEFF-3.0 & JENDL-3.3 \\
\hline Thermal & $(\mathrm{n}, \mathrm{f})$ & 2 & 1.2 & 16 & 1.2 \\
\hline Resonance & $(\mathrm{n}, \mathrm{f})$ & 18 & 386 & 2440 & 433 \\
\hline Unresolved Res. & $(\mathrm{n}, \mathrm{f})$ & 27 & 14 & 134 & 37 \\
\hline High Energy & $(\mathrm{n}, \mathrm{f})$ & 8 & 2.5 & 6.1 & 2.4 \\
\hline \hline
\end{tabular}

\section{Evaluation Date: 1978}

\section{Methodology:}

* (n,res): Fit to resonance data.

* $(\mathrm{n}, \mathrm{f})$ : Fit to experimental data.

* (n,tot), (n,elas), (n, $\gamma), \quad\left(\mathrm{n}, \mathrm{n}^{\prime}\right), \quad(\mathrm{n}, 2 \mathrm{n})$, $(n, 3 n),(n, 4 n)$ : Hauser-Feshbach calculation $[6]$.

ENDL99

Evaluation Date: 1975

Methodology: (See Ref. [10])

* (n,tot), (n,elas): Optical model calculation based on Optical Model potential of Ref. [11].

* (n,f): Fit to experimental data.

* Rest of channels: Systematics based on Ref. [12].

JEFF-3.0

Evaluation Date: 1989

Methodology:

Adopt JENDL-3.2.

JENDL-3.2

Evaluation Date: 1989

Methodology:

* (n,tot): Sum of all channels.

* (n,res): Fit to resonance data.

* $(\mathrm{n}, \mathrm{f})$ : Fit to experimental data.

* (n,elas), (n,n'): Hauser-Feshbach calculation using CASTHY [7] and ECIS [8].

* (n, 2n), (n,3n), (n,4n): Systematics based on [13].

* (n, $\gamma)$ : Based on results of the DSD code $[14]$ and the BROND-2.2 evaluation.

JENDL-3.3

Evaluation Date: 1997

Methodology:

Adopt JENDL-3.2.
${ }^{239} \mathrm{Pu}$

There is extensive data on this isotope for nearly all of the reactions. Due to the wide use of this isotope in technological applications, it is extensively studied. As such, we will adopt the ENDF/B-VII. $\beta 0$ since it was the most recently updated and has the most data underpinning the various cross sections. We will need to revisit this isotope as part of the proposed "Z-chain" effort because ${ }^{239} \mathrm{Pu}$ has the most data of any plutonium isotope so is the best isotope to use in tuning our calculations.

ENDF/B-VI .r8

Evaluation Date: 1989

Methodology:

* (n,tot): Fit to data using HauserFeshbach calculation as prior.

* (n,res): Fit to resonance data [15].

$*(\mathrm{n}, \mathrm{f})$ : Fit to experimental data.

* (n,elas): Subtract other reactions from $(\mathrm{n}, \mathrm{tot})$

$*(\mathrm{n}, \gamma), \quad\left(\mathrm{n}, \mathrm{n}^{\prime}\right), \quad(\mathrm{n}, 2 \mathrm{n}), \quad(\mathrm{n}, 3 \mathrm{n}), \quad(\mathrm{n}, 4 \mathrm{n})$ : Model calculations using combination of GNASH [16], ECIS [8], DWUCK [17] and COMNUC [18].

ENDF/B-VII . $\beta 0$

Evaluation Date: 2003

Methodology:

* $(\mathrm{n}, \mathrm{f})$ : Fit experimental data.

* $(\mathrm{n}, 2 \mathrm{n})$ : Combination of GNASH [16] modeling, systematics and GEANIE data [19].

* Rest of channels: Adopt ENDF/B-VI.r8.

ENDL99

Evaluation Date: 1999

Methodology:

Unclear, no documentation given.

JEFF-3.0

Evaluation Date: 2002

Methodology: 
TABLE II: Comparison of data to evaluations for ${ }^{238} \mathrm{Pu}$.

\begin{tabular}{l|c|c|c|c|c|c}
\hline \hline \multirow{2}{*}{ Energy Range } & \multirow{2}{*}{ Reaction } & $N_{\text {data }}$ & \multicolumn{5}{|c}{$\chi^{2} / N_{\text {data }}$} \\
\cline { 3 - 7 } Thermal & ENDF/B-VI.r8 & ENDL99 & JEFF-3.0 & JENDL-3.3 \\
\cline { 2 - 7 } & $(\mathrm{n}, \mathrm{tot})$ & 99 & 0.073 & 0.15 & 0.088 & 0.088 \\
\cline { 2 - 7 } & $(\mathrm{n}, \gamma)$ & 0 & $\mathrm{n} / \mathrm{a}$ & $\mathrm{n} / \mathrm{a}$ & $\mathrm{n} / \mathrm{a}$ & $\mathrm{n} / \mathrm{a}$ \\
\hline \multirow{4}{*}{ Resonance } & $(\mathrm{n}, \mathrm{f})$ & 23 & 13.4 & 22.4 & 10.5 & 10.5 \\
\cline { 2 - 7 } & $(\mathrm{n}, \mathrm{tot})$ & 620 & 36 & 31 & 90 & 90 \\
\cline { 2 - 7 } & $(\mathrm{n}, \gamma)$ & 2858 & 21 & 20 & 19 & 19 \\
\cline { 2 - 7 } & $(\mathrm{n}, \mathrm{f})$ & 8986 & 729 & 594 & 1391 & 1264 \\
\hline \multirow{3}{*}{ Unresolved Res. } & $(\mathrm{n}, \mathrm{tot})$ & 56 & 0.84 & 0.83 & 0.58 & 0.76 \\
\cline { 2 - 7 } & $(\mathrm{n}, \gamma)$ & 647 & 1.3 & 2.2 & 1.9 & 1.5 \\
\cline { 2 - 7 } & $(\mathrm{n}, \mathrm{f})$ & 4494 & 79 & 85 & 224 & 33 \\
\cline { 2 - 7 } & $(\mathrm{n}, \mathrm{tot})$ & 0 & $\mathrm{n} / \mathrm{a}$ & $\mathrm{n} / \mathrm{a}$ & $\mathrm{n} / \mathrm{a}$ & $\mathrm{n} / \mathrm{a}$ \\
\cline { 2 - 7 } & $(\mathrm{n}, \gamma)$ & 0 & $\mathrm{n} / \mathrm{a}$ & $\mathrm{n} / \mathrm{a}$ & $\mathrm{n} / \mathrm{a}$ & $\mathrm{n} / \mathrm{a}$ \\
\cline { 2 - 7 } & $(\mathrm{n}, \mathrm{f})$ & 250 & 11 & 10 & 9.4 & 9.4 \\
\hline \hline
\end{tabular}

* (n,res): Fit to resonance data [15].

* Rest of channels: Model calculations using combination of GNASH [16] and ECIS [8].

JENDL-3.3

Evaluation Date: 1987

\section{Methodology:}

* (n,tot): Adopt JENDL-2 for low energy portion, fit the higher energy data.

* (n,res) $((\mathrm{n}, \mathrm{f})$ and (n,elas) only): Fit to resonance data [15].

* $(\mathrm{n}, \mathrm{f})$ : Fit to experimental data.

* $(\mathrm{n}, \gamma)$ : Systematics, based on JENDL-2 value and $(n, f)$ result for low energy range, Hauser-Feshbach modeling for higher energy.

* All other channels: Model calculations using combination of GNASH [16] and ECIS [8].

$$
{ }^{240} \mathrm{PU}
$$

There is (n,tot), (n,elas), (n, $\gamma)$ and (n,f) data for this isotope. Unfortunately, the evaluations on this isotope have very large $\chi^{2}$ in comparison to this data. The bad agreement in the $(\mathrm{n}, \mathrm{f})$ cross section seems to be driven by the Weston and Todd data [20] which has 9692 points, nearly $1 / 4$ of which are negative, indicating a bad background subtraction of some type. The bad agreement in the $(\mathrm{n}, \gamma)$ data is driven by another Weston and Todd dataset [21]. This set is a little more confusing since there are no obvious problems with it, other than having a different normalization than the other sets. Finally, we have not tracked down the trouble with the (n,tot) cross section, but expect a similar cause.

The JENDL-3.3 evaluation appears best on the basis of its agreement with the rest of the data and because its high energy cross sections were computed within the same Hauser-Feshbach calculation, implying that the evaluation is internally consistent.

\section{ENDF/B-VI.r8}

Evaluation Date: 1986

\section{Methodology:}

* (n,res): Fit to resonance data, but only data collected before 1975 used.

* (n,elas): Subtract other reactions from $(\mathrm{n}, \mathrm{tot})$.

* (n,f): Fit to experimental data.

* (n,tot), (n,elas), (n, $\gamma), \quad\left(\mathrm{n}, \mathrm{n}^{\prime}\right), \quad(\mathrm{n}, 2 \mathrm{n})$, $(n, 3 n),(n, 4 n)$ : Hauser-Feshbach calculation, but competition fixed by CENDL evaluators.

ENDL99

Evaluation Date: 1976

Methodology: (See Ref. [10])

* (n,tot), (n,elas): Optical model calculation based on Optical Model potential of Ref. [11].

* (n,res): Adopt ENDF/B-V.

* $(\mathrm{n}, \mathrm{f})$ : Fit to experimental data.

* Rest of channels: Systematics based on Ref. [12].

JEFF-3.0

Evaluation Date: 2002 
TABLE III: Comparison of data to evaluations for ${ }^{239} \mathrm{Pu}$.

\begin{tabular}{|c|c|c|c|c|c|c|c|}
\hline \multirow[b]{2}{*}{ Energy Range } & \multirow[b]{2}{*}{ Reaction } & \multirow[b]{2}{*}{$N_{\text {data }}$} & \multicolumn{5}{|c|}{$\chi^{2} / N_{\text {data }}$} \\
\hline & & & ENDF/B-VI.r8 & ENDF/B-VII. $\beta 0$ & ENDL99 & JEFF-3.0 & JENDL -3.3 \\
\hline \multirow[t]{4}{*}{ Thermal } & $(\mathrm{n}$, tot $)$ & 886 & 14.2 & 14.2 & 14.2 & 14.2 & 14.2 \\
\hline & (n,elas) & 0 & $\mathrm{n} / \mathrm{a}$ & $\mathrm{n} / \mathrm{a}$ & $\mathrm{n} / \mathrm{a}$ & $\mathrm{n} / \mathrm{a}$ & $\mathrm{n} / \mathrm{a}$ \\
\hline & $(\mathrm{n}, \gamma)$ & 493 & 0.19 & 0.19 & 10 & 0.19 & 0.19 \\
\hline & $(\mathrm{n}, \mathrm{f})$ & 4442 & 3.95 & 3.95 & 3.95 & 3.95 & 3.95 \\
\hline \multirow[t]{4}{*}{ Resonance } & $(\mathrm{n}$, tot $)$ & 60757 & 2272 & 2272 & 2252 & 2272 & 2272 \\
\hline & (n,elas) & 0 & $\mathrm{n} / \mathrm{a}$ & $\mathrm{n} / \mathrm{a}$ & $\mathrm{n} / \mathrm{a}$ & $\mathrm{n} / \mathrm{a}$ & $\mathrm{n} / \mathrm{a}$ \\
\hline & $(\mathrm{n}, \gamma)$ & 2675 & 94 & 94 & 9.4 & 94 & 94 \\
\hline & $(\mathrm{n}, \mathrm{f})$ & 40271 & 743 & 743 & 743 & 743 & 743 \\
\hline \multirow[t]{5}{*}{ Unresolved Res. } & $(\mathrm{n}$, tot $)$ & 53794 & 138 & 138 & 138 & 138 & 138 \\
\hline & (n,elas) & 3 & 0.82 & 0.83 & 0.68 & 0.82 & 0.58 \\
\hline & $(\mathrm{n}, \gamma)$ & 263 & 25.9 & 25.9 & 13.5 & 26.5 & 26.6 \\
\hline & $(\mathrm{n}, \mathrm{f})$ & 26200 & 50.7 & 50.7 & 5.8 & 49.4 & 51.4 \\
\hline & $\left(n, n^{\prime}\right)$ & 1 & 4.3 & 4.3 & 4.9 & 6.3 & 3.0 \\
\hline \multirow[t]{7}{*}{ High Energy } & (n,tot) & 2293 & 25.5 & 25.5 & 25.5 & 3.6 & 26.5 \\
\hline & (n,elas) & 0 & $\mathrm{n} / \mathrm{a}$ & $\mathrm{n} / \mathrm{a}$ & $\mathrm{n} / \mathrm{a}$ & $\mathrm{n} / \mathrm{a}$ & $\mathrm{n} / \mathrm{a}$ \\
\hline & $(\mathrm{n}, \gamma)$ & 0 & $\mathrm{n} / \mathrm{a}$ & $\mathrm{n} / \mathrm{a}$ & $\mathrm{n} / \mathrm{a}$ & $\mathrm{n} / \mathrm{a}$ & $\mathrm{n} / \mathrm{a}$ \\
\hline & $(\mathrm{n}, \mathrm{f})$ & 411 & 8.1 & 7.7 & 8.1 & 3.4 & 8.0 \\
\hline & $\left(n, n^{\prime}\right)$ & 3 & 0.86 & 0.86 & 0.51 & 1.29 & 0.85 \\
\hline & $(\mathrm{n}, 2 \mathrm{n})$ & 41 & 20.8 & 15.3 & 31.7 & 22.2 & 20.5 \\
\hline & $(n, 3 n)$ & 1 & 4.3 & 4.3 & 1.6 & 4.3 & 4.2 \\
\hline
\end{tabular}

\section{Methodology:}

* (n,res): Fit to resonance data from ORNL using SAMMY [22].

* Rest of channels: Adopt JENDL-3.2 which had previously adopted ENDF/B-VI.r8.

JENDL-3.3

Evaluation Date: 2000

\section{Methodology:}

* (n,res): Fit to resonance data from ORNL using SAMMY [22]. This is probably the same fit used by JEFF-3.0.

* (n,tot): Fit to experimental data.

$*(\mathrm{n}, \mathrm{f})$ : Fit to experimental data.

* (n,elas): Subtract other channels from (n,tot).

* Rest of channels: Hauser-Feshbach calculation.

$$
{ }^{241} \mathrm{PU}
$$

There are sufficient data on $(n, f),(n, \gamma)$ and $(n$, tot $)$ at low energies to do a reasonable job fitting (n,res). Furthermore, there is enough high energy $(\mathrm{n}, \mathrm{f})$ data to fit the entire energy range from 1-20 MeV with the exception of a gap between 9-12 MeV.

The (n,res) data from the JENDL-3.3 evaluation is probably the best to use simply because it was reanalyzed most recently. However, there is no high-energy data other than $(\mathrm{n}, \mathrm{f})$ and thus no way to assess the quality of the high energy reaction modeling. We suspect that the competition between fission and the other channels was not properly accounted. Given this, we would like to reinvestigate this isotope as part of the proposed "Z-chain" analysis.

\section{ENDF/B-VI.r8}

Evaluation Date: 1994

\section{Methodology:}

* (n,res): Fit to resonance data [23].

* Rest of channels: Unclear, method not documented.

ENDF/B-VII. $\beta 0$

Evaluation Date: 2003

\section{Methodology:}

* (n,res): Fit to resonance data. Improved on Ref. [23] by adding more data.

* Rest of channels: Adopt ENDF/B-VI.r8. 
TABLE IV: Comparison of data to evaluations for ${ }^{240} \mathrm{Pu}$.

\begin{tabular}{l|c|c|c|c|c|c}
\hline \multirow{3}{*}{ Energy Range } & \multirow{2}{*}{ Reaction } & $N_{\text {data }}$ & \multicolumn{5}{|c}{$\chi^{2} / N_{\text {data }}$} \\
\cline { 3 - 7 } Thermal & ENDF/B-VI.r8 & ENDL99 & JEFF-3.0 & JENDL-3.3 \\
\cline { 2 - 7 } & $(\mathrm{n}$, tot $)$ & 394 & 0.17 & 0.70 & 0.17 & 0.20 \\
\cline { 2 - 7 } & $(\mathrm{n}, \mathrm{elas})$ & 0 & $\mathrm{n} / \mathrm{a}$ & $\mathrm{n} / \mathrm{a}$ & $\mathrm{n} / \mathrm{a}$ & $\mathrm{n} / \mathrm{a}$ \\
\cline { 2 - 7 } & $(\mathrm{n}, \gamma)$ & 2 & 1.0 & $>10^{5}$ & 3.4 & 0.02 \\
\cline { 2 - 7 } Resonance & $(\mathrm{n}, \mathrm{f})$ & 23 & 5.1 & 5.0 & 4.4 & 4.4 \\
\cline { 2 - 7 } & $(\mathrm{n}, \mathrm{tot})$ & 25378 & $>10^{4}$ & $>10^{5}$ & $>10^{5}$ & $>10^{5}$ \\
\cline { 2 - 7 } & $(\mathrm{n}, \mathrm{elas})$ & 0 & $\mathrm{n} / \mathrm{a}$ & $\mathrm{n} / \mathrm{a}$ & $\mathrm{n} / \mathrm{a}$ & $\mathrm{n} / \mathrm{a}$ \\
\cline { 2 - 7 } & $(\mathrm{n}, \gamma)$ & 8 & $>10^{5}$ & 204 & $>10^{5}$ & $>10^{5}$ \\
\cline { 2 - 7 } & $(\mathrm{n}, \mathrm{f})$ & 9099 & $>10^{7}$ & $>10^{7}$ & $>10^{7}$ & $>10^{7}$ \\
\hline \multirow{5}{*}{ Unresolved Res. } & $(\mathrm{n}, \mathrm{tot})$ & 13473 & 18 & 25 & 28 & 30 \\
\cline { 2 - 7 } & $(\mathrm{n}, \mathrm{elas})$ & 14 & 0.15 & 0.02 & 0.07 & 0.07 \\
\cline { 2 - 7 } & $(\mathrm{n}, \gamma)$ & 25 & 32 & 150 & 29 & 19 \\
\cline { 2 - 7 } & $(\mathrm{n}, \mathrm{f})$ & 5985 & $>10^{6}$ & $>10^{6}$ & $>10^{5}$ & $>10^{5}$ \\
\hline & $(\mathrm{n}, \mathrm{tot})$ & 112 & 14.2 & 25.7 & 14.1 & 14.1 \\
\cline { 2 - 7 } & $(\mathrm{n}, \mathrm{elas})$ & 16 & 0.45 & 0.29 & 0.86 & 0.65 \\
\cline { 2 - 7 } & $(\mathrm{n}, \gamma)$ & 0 & $\mathrm{n} / \mathrm{a}$ & $\mathrm{n} / \mathrm{a}$ & $\mathrm{n} / \mathrm{a}$ & $\mathrm{n} / \mathrm{a}$ \\
\cline { 2 - 7 } & $(\mathrm{n}, \mathrm{f})$ & 249 & 8.8 & 12.2 & 8.9 & 8.9 \\
\hline \hline
\end{tabular}

ENDL99

Evaluation Date: 1972

Methodology: (See Ref. [10])

* (n,tot), (n,elas): Optical model calculation based on Optical Model potential of Ref. [11].

* $(\mathrm{n}, \mathrm{f})$ : Fit to experimental data.

* Rest of channels: Systematics based on Ref. [12].

$\mathrm{JEFF}-3.0$

Evaluation Date: 1987

Methodology:

Adopt JENDL-3.2.

JENDL-3. 2

Evaluation Date: Unknown

Methodology:

* (n,res): Fit to resonance data [23].

* (n,f): Fit to experimental data.

* Rest of channels: Hauser-Feshbach calculation using CASTHY [7].

\section{Comments:}

It is unclear whether the evaluators accounted for the competition between fission and the other channels in their evaluation since the fission channel was fit to data and apparently not included in any Hauser-Feshbach calculations.
JENDL-3.3

Evaluation Date: 2000

\section{Methodology:}

* (n,res): Fit to resonance data. Improved on Ref. [23] by adding more data. This is probably the evaluation adopted by ENDF/B-VII. $\beta 0$.

* Rest of channels: Adopt JENDL-3.2.
There is cross section data for this isotope, but it is of inconsistent quality. Only $(n, f)$ has high quality data. For $(n, \gamma)$ there are two data sets and neither have uncertainties. For (n,tot), there are several datasets, but only one that has uncertainties and $E_{\text {inc }}>1 \mathrm{MeV}$. In either case, we assumed a $10 \%$ uncertainty in order to compute the $\chi^{2}$ for evaluation scoring. For (n,elas), there are only three data points and they are clustered about $1 \mathrm{MeV}$.

Looking over all of the evaluations, there is none that is guaranteed to be internally consistent (in that the competition between the various channels is properly accounted for), but JEFF-3.0 comes closest. According to the JEFF-3.0 documentation, the $(n, f)$ cross section was tuned in some of the evaluators' Hauser-Feshbach calculations. The $(n, \gamma)$ and $(n, 4 n)$ cross sections should be revisited to ensure that they are consistent.

$\mathrm{ENDF} / \mathrm{B}-\mathrm{VI} \cdot \mathrm{r} 8$ 
TABLE V: Comparison of data to evaluations for ${ }^{241} \mathrm{Pu}$. JENDL-3.2 not included in this list since other databases are derived from it.

\begin{tabular}{|c|c|c|c|c|c|c|c|}
\hline \multirow[b]{2}{*}{ Energy Range } & \multirow[b]{2}{*}{ Reaction } & \multirow[b]{2}{*}{$N_{\text {data }}$} & \multicolumn{5}{|c|}{$\chi^{2} / N_{\text {data }}$} \\
\hline & & & ENDF/B-VI.r8 & ENDF/B-VII. $\beta 0$ & ENDL99 & JEFF-3.0 & JENDL -3.3 \\
\hline \multirow[t]{4}{*}{ Thermal } & $(\mathrm{n}$, tot $)$ & 1235 & 4540 & 4470 & 5530 & 4470 & 4540 \\
\hline & (n,elas) & 0 & $\mathrm{n} / \mathrm{a}$ & $\mathrm{n} / \mathrm{a}$ & $\mathrm{n} / \mathrm{a}$ & $\mathrm{n} / \mathrm{a}$ & $\mathrm{n} / \mathrm{a}$ \\
\hline & $(\mathrm{n}, \gamma)$ & 307 & 2.0 & 2.0 & 2.9 & 2.0 & 2.0 \\
\hline & $(\mathrm{n}, \mathrm{f})$ & 3429 & 21 & 20 & 35 & 20 & 21 \\
\hline \multirow[t]{4}{*}{ Resonance } & (n,tot) & 44394 & 31 & 32 & 207 & 32 & 31 \\
\hline & (n,elas) & 299 & 1.08 & 1.13 & 1.64 & 1.13 & 1.08 \\
\hline & $(\mathrm{n}, \gamma)$ & 1840 & 2119 & 2118 & 6584 & 2472 & 2472 \\
\hline & $(\mathrm{n}, \mathrm{f})$ & 23651 & 86 & 87 & 1185 & 86 & 85 \\
\hline \multirow[t]{4}{*}{ Unresolved Res. } & (n,tot) & 14972 & 4.3 & 4.3 & 6.4 & 4.2 & 4.2 \\
\hline & $(\mathrm{n}, \mathrm{elas})$ & 0 & $\mathrm{n} / \mathrm{a}$ & $\mathrm{n} / \mathrm{a}$ & $\mathrm{n} / \mathrm{a}$ & $\mathrm{n} / \mathrm{a}$ & $\mathrm{n} / \mathrm{a}$ \\
\hline & $(\mathrm{n}, \gamma)$ & 772 & 253 & 253 & 183 & 246 & 246 \\
\hline & $(\mathrm{n}, \mathrm{f})$ & 3448 & 43 & 43 & 41 & 42 & 42 \\
\hline \multirow[t]{4}{*}{ High Energy } & (n,tot) & 0 & $\mathrm{n} / \mathrm{a}$ & $\mathrm{n} / \mathrm{a}$ & $\mathrm{n} / \mathrm{a}$ & $\mathrm{n} / \mathrm{a}$ & $\mathrm{n} / \mathrm{a}$ \\
\hline & (n,elas) & 0 & $\mathrm{n} / \mathrm{a}$ & $\mathrm{n} / \mathrm{a}$ & $\mathrm{n} / \mathrm{a}$ & $\mathrm{n} / \mathrm{a}$ & $\mathrm{n} / \mathrm{a}$ \\
\hline & $(\mathrm{n}, \gamma)$ & 0 & $\mathrm{n} / \mathrm{a}$ & $\mathrm{n} / \mathrm{a}$ & $\mathrm{n} / \mathrm{a}$ & $\mathrm{n} / \mathrm{a}$ & $\mathrm{n} / \mathrm{a}$ \\
\hline & $(\mathrm{n}, \mathrm{f})$ & 64 & 11.5 & 11.5 & 11.2 & 12.1 & 11.9 \\
\hline
\end{tabular}

Evaluation Date: 1978

\section{Methodology:}

* (n,res): Unclear combination of resonance data and systematics based on Ref. [24].

* (n,f): Unclear combination of fit to experimental data and Hauser-Feshbach modeling.

* Rest of channels: Hauser-Feshbach calculation using COMNUC [18] and JUKARL [25].

ENDL99

Evaluation Date: 1978

Methodology: (See Ref. [10])

* (n,tot), (n,elas): Optical model calculation based on Optical Model potential of Ref. [11].

* $(\mathrm{n}, \mathrm{f})$ : Fit to experimental data.

* Rest of channels: Systematics based on Ref. [12].

JEFF-3.0

Evaluation Date: 1998

Methodology:

* (n,res): Unclear, not well documented

* (n,elas): Subtract other reactions from $(\mathrm{n}$, tot $)$.

* $(\mathrm{n}, \gamma),(\mathrm{n}, 4 \mathrm{n}):$ Adopt JENDL-3.2. $*(\mathrm{n}, \mathrm{tot}), \quad(\mathrm{n}, \mathrm{f}), \quad\left(\mathrm{n}, \mathrm{n}^{\prime}\right), \quad(\mathrm{n}, 2 \mathrm{n}), \quad(\mathrm{n}, 3 \mathrm{n})$ : Hauser-Feshbach calculation, tuned to get fission competition correct.

JENDL-3. 2

Evaluation Date: 1994

Methodology:

* (n,res): Unclear combination of resonance data and systematics based on Ref. [24].

* (n,tot): Fit to experimental data.

* (n,elas): Subtract other reactions from $(\mathrm{n}$, tot $)$

* $(\mathrm{n}, \mathrm{f})$ : Fit to experimental data.

$*(\mathrm{n}, \gamma), \quad\left(\mathrm{n}, \mathrm{n}^{\prime}\right)$ : Hauser-Feshbach calculation using CASTHY [7].

* (n,2n),(n,3n), (n,4n): Systematics based on Ref. [26].

JENDL-3. 3

Evaluation Date: 2000

\section{Methodology:}

* (n,res): Unclear combination of resonance data and systematics based on Ref. [24]. There is more data in this set than is used in ENDF/B-VI.r8.

* (n,elas): Subtract other reactions from $(\mathrm{n}, \mathrm{tot})$.

* (n,tot), (n,f), (n, $\gamma)$ : Adopt JENDL-3.2.

* (n,n'): Hauser-Feshbach calculation.

* $(\mathrm{n}, 2 \mathrm{n}),(\mathrm{n}, 3 \mathrm{n})(\mathrm{n}, 4 \mathrm{n})$ : Same systematics at JENDL-3.2, but with improved inputs. 
TABLE VI: Comparison of data to evaluations for ${ }^{242} \mathrm{Pu}$. JENDL-3.2 not included in this list since other databases are derived from it.

\begin{tabular}{|c|c|c|c|c|c|c|}
\hline \multirow[b]{2}{*}{ Energy Range } & \multirow[b]{2}{*}{ Reaction } & \multirow[b]{2}{*}{$N_{\text {data }}$} & \multicolumn{4}{|c|}{$\chi^{2} / N_{\text {data }}$} \\
\hline & & & ENDF/B-VI.r8 & ENDL99 & JEFF-3.0 & JENDL-3.3 \\
\hline \multirow[t]{4}{*}{ Thermal } & $(\mathrm{n}, \mathrm{tot})$ & 208 & 0.35 & 1.17 & 0.34 & 0.34 \\
\hline & (n,elas) & 0 & $\mathrm{n} / \mathrm{a}$ & $\mathrm{n} / \mathrm{a}$ & $\mathrm{n} / \mathrm{a}$ & $\mathrm{n} / \mathrm{a}$ \\
\hline & $(\mathrm{n}, \gamma)$ & 1 & 0.5 & 0.10 & 0 & 0 \\
\hline & $(\mathrm{n}, \mathrm{f})$ & 1 & 0 & 0 & 0 & 0 \\
\hline \multirow[t]{4}{*}{ Resonance } & $(\mathrm{n}$, tot $)$ & 1062 & 83 & 212 & 79 & 79 \\
\hline & (n,elas) & 0 & $\mathrm{n} / \mathrm{a}$ & $\mathrm{n} / \mathrm{a}$ & $\mathrm{n} / \mathrm{a}$ & $\mathrm{n} / \mathrm{a}$ \\
\hline & $(\mathrm{n}, \gamma)$ & 0 & $\mathrm{n} / \mathrm{a}$ & $\mathrm{n} / \mathrm{a}$ & $\mathrm{n} / \mathrm{a}$ & $\mathrm{n} / \mathrm{a}$ \\
\hline & $(\mathrm{n}, \mathrm{f})$ & 4689 & 94 & 37 & 27 & 28 \\
\hline \multirow[t]{4}{*}{ Unresolved Res. } & $(\mathrm{n}$, tot $)$ & 65 & 0.7 & 5.5 & 1.4 & 5.0 \\
\hline & (n,elas) & 2 & 1.23 & 0.28 & 0.27 & 0.23 \\
\hline & $(\mathrm{n}, \gamma)$ & 250 & 50 & 28 & 54 & 54 \\
\hline & $(\mathrm{n}, \mathrm{f})$ & 3576 & 2.0 & 3.0 & 0.4 & 3.0 \\
\hline \multirow[t]{4}{*}{ High Energy } & $(\mathrm{n}, \mathrm{tot})$ & 103 & 674 & 675 & 666 & 666 \\
\hline & (n,elas) & 1 & 0.19 & 0.77 & 1.26 & 1.35 \\
\hline & $(\mathrm{n}, \gamma)$ & 0 & $\mathrm{n} / \mathrm{a}$ & $\mathrm{n} / \mathrm{a}$ & $\mathrm{n} / \mathrm{a}$ & $\mathrm{n} / \mathrm{a}$ \\
\hline & $(\mathrm{n}, \mathrm{f})$ & 374 & 7.6 & 9.0 & 2.7 & 6.5 \\
\hline
\end{tabular}

$$
{ }^{243} \mathrm{PU}
$$

There is only one dataset for this reaction, the surrogate $(\mathrm{n}, \mathrm{f})$ cross section analysis of Younes and Britt [1]. None of the evaluations come close to this dataset. Furthermore, the evaluations are essentially undocumented as both ENDF/B-VI.r8 and JEFF-3.0 are derived from ENDL99. Finally, the (n,res) cross sections are "picket fences." Although we can not improve on the (n,res) data, we could improve on all of the reactions as part of the proposed "Z-chain" analysis, taking the Younes and Britt data into account.

ENDF/B-VI.r8

Evaluation Date: 1976

Methodology:

* (n,res): Fit to resonance data using GENPAR [5].

* Rest of channels: Adopt ENDL99 [12] .

\section{ENDL99}

Evaluation Date: 1975

Methodology: (See Ref. [10])

* (n,tot), (n,elas): Optical model calculation based on Optical Model potential of Ref. [11].

* (n,res): Adopt evaluation of McCrosson which most likely is the one in reference [5].

* (n,f): Fit to experimental data.
* Rest of channels: Systematics based on Ref. [12].

JEFF-3. 0

Evaluation Date: 1982

Methodology:

Adopt ENDF/B-V which is now ENDF/B-VI.r8.

$$
{ }^{244} \mathrm{PU}
$$

There is only $(\mathrm{n}, \mathrm{f})$ data for this isotope and there is a severe conflict in the data in the region $0.8<E_{\text {inc }}<10$ $\mathrm{MeV}$ : roughly half the datasets are $50 \%$ higher than the other half. This conflict is not resolvable without further experimental work.

Out of the three evaluations available for this isotope, only JENDL-3.3 has been compared to any data taken after 1978. However, the JENDL-3.3 evaluation uses two separate sets of calculations for the (n, $\gamma)$ and (n,n') channels and the $(n, f),(n, 2 n),(n, 3 n)$ and $(n, 4 n)$ channels so there is no way to guarantee that the cross sections are internally consistent. Since the $(n, f)$ is the largest channel, it is likely that the $(\mathrm{n}, 2 \mathrm{n}),(\mathrm{n}, 3 \mathrm{n})$ and $(\mathrm{n}, 4 \mathrm{n})$ channels have the right competition but the (n, $\gamma$ ) and (n,n') channels for sure do not. Given this, we would like to revisit this isotope as part of the proposed "Z-chain" project.

\section{ENDF/B-VI.r8}

Evaluation Date: 1978

Methodology: 
TABLE VII: Comparison of data to evaluations for ${ }^{243} \mathrm{Pu}$.

\begin{tabular}{l|c|c|c|c|c}
\hline \hline & & \multirow{3}{|c}{$\chi^{2} / N_{\text {data }}$} \\
\cline { 4 - 6 } Energy Range & Reaction & $N_{\text {data }}$ & ENDF/B-VI.r8 & ENDL99 & JEFF-3.0 \\
\hline Thermal & $(\mathrm{n}, \mathrm{f})$ & 0 & $\mathrm{n} / \mathrm{a}$ & $\mathrm{n} / \mathrm{a}$ & $\mathrm{n} / \mathrm{a}$ \\
\hline Resonance & $(\mathrm{n}, \mathrm{f})$ & 0 & $\mathrm{n} / \mathrm{a}$ & $\mathrm{n} / \mathrm{a}$ & $\mathrm{n} / \mathrm{a}$ \\
\hline Unresolved Res. & $(\mathrm{n}, \mathrm{f})$ & 18 & 34 & 34 & 34 \\
\hline High Energy & $(\mathrm{n}, \mathrm{f})$ & 30 & 10 & 10 & 10 \\
\hline \hline
\end{tabular}

* (n,res): Fit to resonance data using GENPAR [5], but only data prior to 1978 used.

* (n,tot): Sum of all channels.

* Rest of channels: Hauser-Feshbach calculation [6]. It was tuned to reproduce some fission data, although the (n,2n) cross section has a strange shape.

\section{Comments:}

This evaluation is identical to ENDF/B-V.

JEFF-3.0

Evaluation Date: 1982

Methodology:

Adopt JEF-2 which is was adopted from $E N D F / B-V$. ENDF/B-V is identical to ENDF/B-VI.r8.

JENDL-3. 3

Evaluation Date: 1995

\section{Methodology:}

* (n,res): Fit to data from Mughabghab $[24]$.

* (n,tot), (n,elas): Calculations using ECIS [8].

* $(\mathrm{n}, \mathrm{f}), \quad(\mathrm{n}, 2 \mathrm{n}), \quad(\mathrm{n}, 3 \mathrm{n}), \quad(\mathrm{n}, 4 \mathrm{n}): \quad$ HauserFeshbach calculations using STAPRE [9] and ECIS [8]. Below $8 \mathrm{MeV}$, the $(\mathrm{n}, \mathrm{f})$ cross section is "determined by eyeguiding of experimental data."

* $(\mathrm{n}, \gamma), \quad\left(\mathrm{n}, \mathrm{n}^{\prime}\right)$ : Hauser-Feshbach calculations using CASTHY [7] and ECIS [8].

\section{Comments:}

Since STAPRE was used for some of the reactions and CASTHY for others, there will be problems with competition between the various channels. Since $(n, f)$ is the largest channel and it is computed within the STAPRE set of calculations, we expect the competition problems to be largest with the $(n, \gamma)$ and $\left(n, n^{\prime}\right)$ cross sections.
${ }^{245} \mathrm{Pu}$

There are no evaluations for this isotope. We would like to investigate this isomer as part of the proposed "Z-chain" analysis.

$$
{ }^{246} \mathrm{PU}
$$

There is no data on any reaction on this isotope. There is only one evaluation, namely that in JENDL-3.3. It is doubtful we could produce a better estimate of $(n, r e s)$ than that in JENDL-3.3, but we can redo the HauserFeshbach calculations as part of our proposed "Z-chain" re-evaluation effort. Indeed, this is the only realistic way to assess whether any of the JENDL-3.3 evaluation is salvageable.

JENDL-3.3

Evaluation Date: 1995

\section{Methodology:}

* (n,res): Taken to be a constant, based on systematics.

* (n,tot), (n, $\gamma), \quad\left(\mathrm{n}, \mathrm{n}^{\prime}\right)$ : Hauser-Feshbach (CASTHY) calculations [7].

* (n,f), (n,2n), (n,3n), (n,4n): HauserFeshbach (STAPRE) calculations [9].

* (n,elas): Obtained by subtracting the sum of all other channels from (n,tot).

\section{Comments:}

Since STAPRE was used for some of the reactions and CASTHY for others, there will be problems with competition between the various channels. Since $(n, f)$ is the largest channel and it is computed within the STAPRE set of calculations, we expect the competition problems to be largest with the $(\mathrm{n}, \gamma)$ and $\left(\mathrm{n}, \mathrm{n}^{\prime}\right)$ cross sections. Unfortunately, the evaluators rely on the STAPRE fission model which is not very good. Finally, their (n,res) cross sections are constants and purely based on systematics. 
TABLE VIII: Comparison of data to evaluations for ${ }^{244} \mathrm{Pu}$. JENDL-3.2 not included in this list since other databases are derived from it.

\begin{tabular}{l|c|c|c|c|c}
\hline \hline & & & \multicolumn{3}{|c}{$\chi^{2} / N_{\text {data }}$} \\
\cline { 4 - 6 } Energy Range & Reaction & $N_{\text {data }}$ & ENDF/B-VI.r8 & JEFF-3.0 & JENDL-3.3 \\
\hline Thermal & $(\mathrm{n}, \mathrm{f})$ & 0 & $\mathrm{n} / \mathrm{a}$ & $\mathrm{n} / \mathrm{a}$ & $\mathrm{n} / \mathrm{a}$ \\
\hline Resonance & $(\mathrm{n}, \mathrm{f})$ & 5224 & 0.49 & 0.49 & 0.25 \\
\hline Unresolved Res. & $(\mathrm{n}, \mathrm{f})$ & 2802 & 1.42 & 1.42 & 1.13 \\
\hline High Energy & $(\mathrm{n}, \mathrm{f})$ & 154 & 49 & 49 & 59 \\
\hline \hline
\end{tabular}

ACKNOWLEDGments

This work was performed under the auspices of the U.S. Department of Energy by Lawrence Livermore Na- tional Laboratory under Contract W-7405-Eng-48.
[1] W. Younes, H.C. Britt " Tables of neutron induced fission cross sections for various $\mathrm{Pu}, \mathrm{U}$ and Th isotopes, deduced from measured fission probabilities," UCRL-ID-152906 (2003).

[2] W.E. Ormand, private communication.

[3] D.A. Brown, D.P. McNabb, B. Beck, "Update of ENDL $\mathrm{U}(\mathrm{n}, 2 \mathrm{n}), \mathrm{U}(\mathrm{n}, \gamma)$, and $\mathrm{U}(\mathrm{n}, \mathrm{f})$ evaluations," LLNL Internal Report UCRL-TR-202393 (2004).

[4] D.A. Brown, B. Loyola, "Big Actinide Scorecard," http: //nuclear.llnl.gov/CNP/allActinides/.

[5] F. J. McCrosson, "Neutron Cross Sections for Science and Technology," Conference, 15-17 March 1971, Knoxville, TN, p.714. (1971).

[6] F.M. Mann, R.E. Schenter, Trans. Amer. Nucl. Soc. 23, 546 (1976); HEDL TME-77-54 (1977).

[7] S. Igarasi, Fukahori, "Program CASTHY - Statistical Model Calculation for Neutron Cross Sections and Gamma Ray Spectrum," JAERI 1321, NEANDC(J)156/U, INDC(JPN)-143/L (1991).

[8] J. Raynal, "ECIS96," Proceedings of the Specialists' Meeting on the Nucleon Nucleus Optical Model up to 200 MeV, 13-15 November 1996, Bruyères-le-Chatel, France Publication 19 Nuclear Energy Agency, p.159-166 (1996).

[9] M. Uhl and B. Strohmaier, IRK 76/01, Institut für Radiumforschung und Kernphysik der Österreichischen (1976); H. Vonach, UCID-19549, Lawrence Livermore National Laboratory (1982).

[10] R.J. Howerton, M.H. MacGregor, UCRL 50400, Vol 15, Part D (Descriptions) (1978).

[11] F.D. Becchetti, G.W. Greenlees, Phys. Rev. 182, 1190 (1969).

[12] R.J. Howerton, UCRL 50400, Vol 15, Part A (Methods), (1975); Part B (Curves), (1976).

[13] S. Pearlstein, Nucl. Sci. Eng. 23, 238 (1965).

[14] T. Kawano, "Direct-SemiDirect (DSD) Code," private communication.
[15] H. Derrien, J. Nucl. Sci. Tech. 30, 845 (1993).

[16] P.G. Young, E.D. Arthur, and M.B. Chadwick, "Proceedings of the Workshop: "Nuclear Reaction Data and Nuclear Reactions - Physics, Design, and Safety - Vol. 1"," International Centre for Theoretical Physics, Trieste, Italy, 15 April-17 May, 1996, pp 227-404, ed. A. Gandini and G. Reffo. World Scientific, Singapore, (1999).

[17] P.D. Kunz, "General Description of DWUCK4," (1978); "Instructions for the Use of DWUCK, A Distorted Wave Born Approximation Program," COO-535-606.

[18] C.L. Dunford, "Compound Nucleus Reaction Analysis Programs COMNUC and CASCADE," T1-707-130-013 Atomics International (1971).

[19] D. McNabb, J. D. Anderson, R. W. Bauer, J. A. Becker, F. Dietrich, P. Navratil, M. B. Chadwick and P. G. Young, "Evaluation of the ${ }^{239} \mathrm{Pu}(\mathrm{n}, 2 \mathrm{n})$ Integrated Cross Section," LLNL Internal Report UCRL-ID-143328 (2001).

[20] L.W. Weston and J.H. Todd, Nucl. Sci. Eng. 88, 567 (1984).

[21] L.W. Weston and J.H. Todd, Nucl. Sci. Eng. 63, 143 (1977).

[22] N. M. Larson, "Updated Users' Guide for SAMMY: Multilevel R-Matrix Fits to Neutron Data Using Bayes' Equations," ORNL/TM-9179 (1984), ORNL/TM-9179/R1 (1985), ORNL/TM-9179/R2 (1989), ORNL/TM-9179/R3 (1996), ORNL/TM9179/R4 (1998), ORNL/TM-9179/R5 (2000).

[23] H. Derrien, G. de Saussure Nucl. Sci. Eng. 106, 425 (1990); H. Derrien JAERI-M 93-251 (1994).

[24] S.F. Mughabghab, "Neutron Cross Sections, Vol. 1, Part B," Academic Press (1984).

[25] H.Rebel, G.W.Schweimer, KFK-133 (1971).

[26] Segev, Ann. Nucl. Energy, 5, 239 (1978). 